\title{
ULTRASOUND MIS-DIAGNOSIS OF BILIARY SLUDGE AS A GALL BLADDER NEOPLASM-A CAE REPORT
}

*O.U Ogbeide (MBBS, FMCR), *O Asemota (MBBS)

*Department of Radiology University of Benin Teaching Hospital, Benin-City, Nigeria

\author{
Correspondence: \\ Dr Ogbeide Osesogie Usuale \\ Department of Radiology \\ University of Benin Teaching Hospital, \\ Benin-City, Nigeria
}

\section{SUMMARY}

Background: Cholecystosonography is the Ultrasound examination of the gall bladder and ducts. It has the advantage of not using ionising radiation, but may be operator dependent. Thus misinterpretation of the images may sometimes occur especially in the untrained hands.

Case Report: A 24 year old male student was admitted into the medical ward of the University of Benin Teaching Hospital (UBTH) with symptoms of weakness, fever, nausea, pruritus, passage of yellowish urine, jaundice of about 4 weeks. Initial ultrasound examination done by a private practitioner interpreted the image findings as gall bladder tumor. Subsequently, the patient was referred to the UBTH, Nigeria.

There the repeat scan done revealed the diagnosis of biliary sludge. Patient was treated appropriately.

Conclusion: By this report, the possibility of misinterpretation of ultrasound images is documented, especially by untrained personnel is highlighted.

KEY WORDS: Cholecystosonography, Biliary sludge, Interpretation, Misdiagnosis.

\section{BACKGROUND}

The term biliary sludge described bile stones which are in a gel form or thick bile that contains numerous crystals or micro-spheroliths of calcium bilirubinate granules and cholesterol crystals, glycoproteins, calcium carbonate or phosphate or palmitate. These crystals determine the degree of radio-opacity and thus was initially termed "limy-bile" or biliary sound, or milk of calcium bile when seen on plain abdominal radiographs. ${ }^{1-3} \quad$ Biliary sludge is formed frequently under normal conditions, but either dissolves or is cleared by the gall bladder and only in about $15 \%$ of patients does it persist to form cholesterol stones. ${ }^{3}$ The mechanism of formation of biliary sludge is unknown but there is an association with biliary stasis secondary to prolonged fasting, parenteral nutrition, hyperalimentation, haemolysis, cystic duct obstruction, acute and chronic cholecystitis. ${ }^{4-6}$

The possibility of biliary sludge being mis-diagnosed as gallbladder tumour and the value of abdominal ultrasonography in differentiating one from the other is the rational for this case.

\section{Case Report}

CK, a 24 year old male student was admitted into the Medical Ward of the University of Benin Teaching Hospital with symptoms of weakness, fever, nausea, pruritus, passage of yellowish urine, jaundice of about 4 weeks duration. There was no history of intravenous drug administration or blood transfusion or use of native

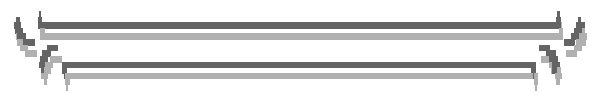


concoctions. He had an abdominal ultrasound scan done in a private hospital prior to presentation, and was told that he had gall bladder carcinoma. He was then given a referral for expert surgical management at the University of Benin Teaching Hospital.

On examination, he was pale, severely icteric, and afebrile. There was no evidence of pedal oedema or peripheral lymphadenopathy. The liver, spleen and both kidneys were not palpable. The urinalysis showed excess of urobilinogen and traces of ketones. The serum bilirubin total was elevated $(34.6 \mathrm{mg} / \mathrm{dl})$, the direct serum bilirubin about $27 \mathrm{mg} / \mathrm{dl}$, serum urea $(27 \mathrm{mg} / \mathrm{dl})$ as Alkaline phosphatase (67 iu) was also elevated. The provisional diagnosis was obstructive jaundice. The differentials were chronic cholecystitis and infective hepatitis. Abdominal ultrasound examination showed moderate hepatomegaly measuring about $3.1 \mathrm{~cm}$ below the right costal margin. It also revealed normal hepatic parenchyma and dilated intrahepatic biliary radicles. The left hepatic duct measured about $8 \mathrm{~mm}$, common hepatic duct about $15 \mathrm{~mm}$ and common bile duct was $23 \mathrm{~mm}$ in size. The gall bladder was enlarged showing normal wall thickness and an intrinsic nonshadowing echogenic homogenous mass measuring about $11.4 \times 5.6 \times$ $6.7 \mathrm{~cm}$ which changed position very slowly with changes in the patient's position. (Figures 1\&2) There was no evidence of gallstones within the intrahepatic biliary radicles / cystic duct or common bile duct. The diagnosis was that of sludge within the gall bladder.

Subsequently, the patient had cholecytectomy and histology confirmed chronic cholecystits. His clinical condition improved and was discharged for out-patient follow-up.

Figure 1: Sonogram of longitudinal section of the distended gall bladder showing an intrinsic non-shadowing echogenic homogenous 'soft-tissue' mass. 


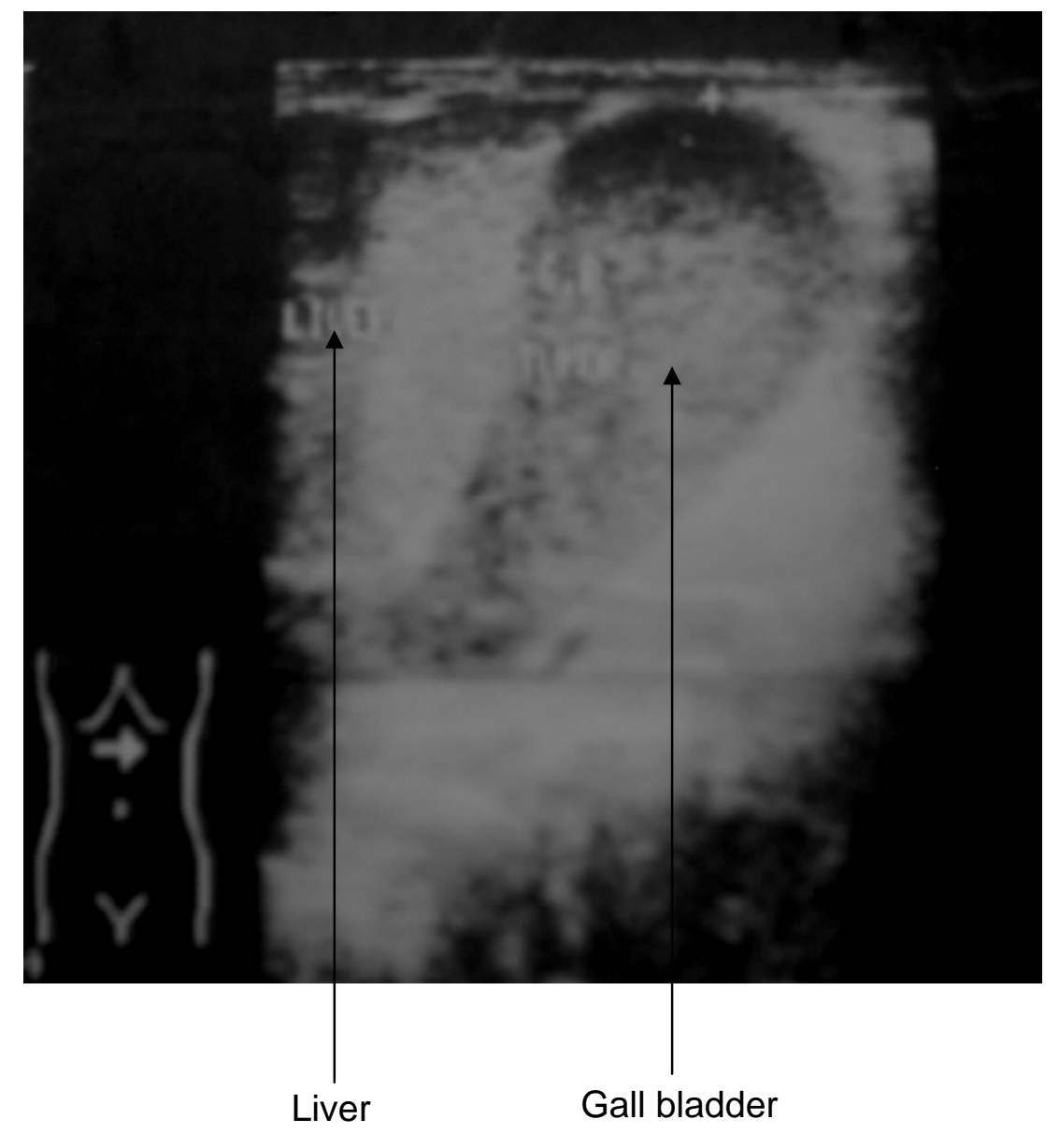

Figure 2: $\quad$ Sonogram of oblique section of the distended gall bladder showing non-shadowing echogenic homogenous soft tissue mass with a fluidfluid level.

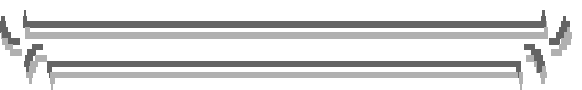




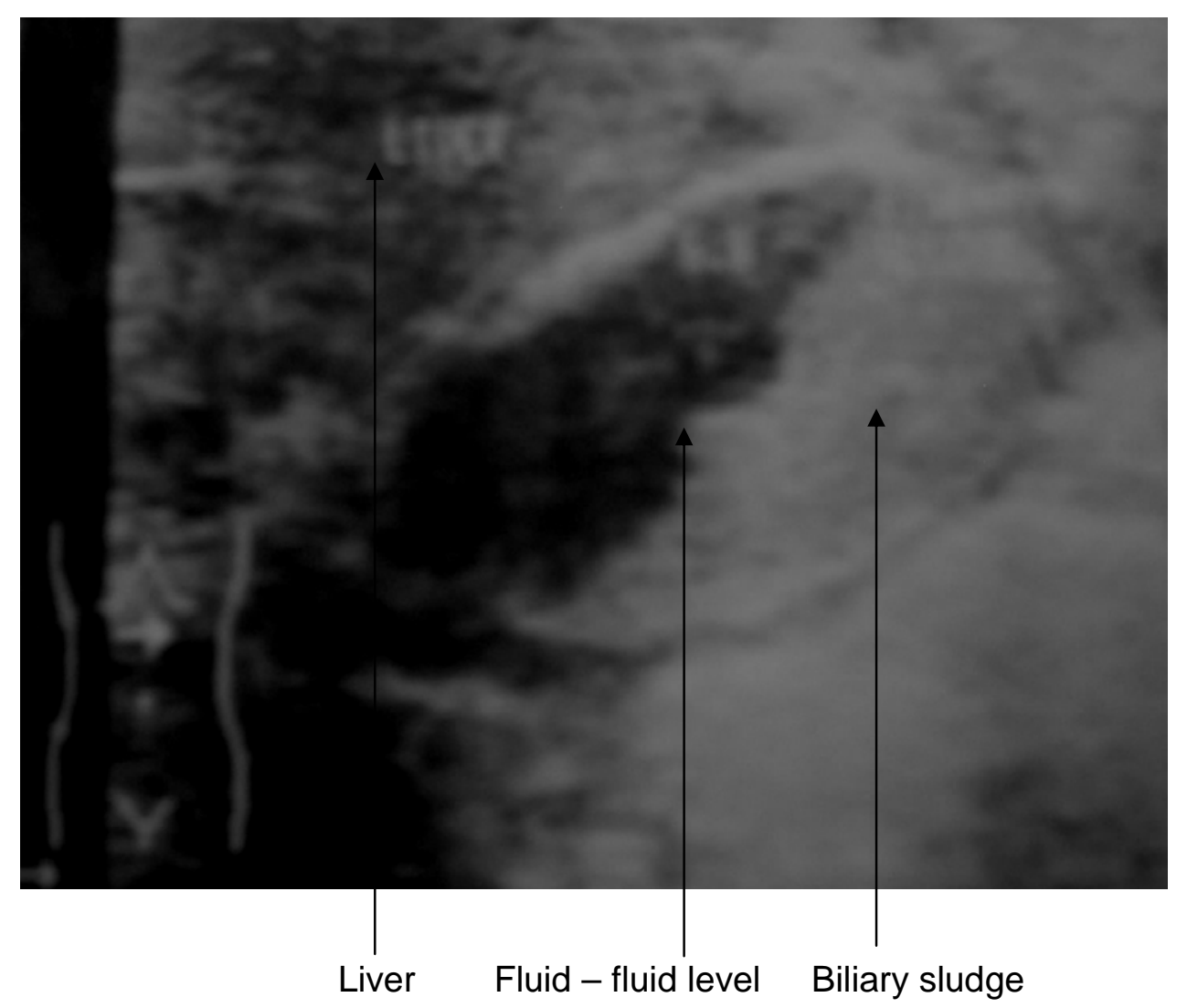

\section{DISCUSSION}

Gall bladder disease rank among the common causes of abdominal pain in adults, while approximately 500,000 cholecystectomies are performed in each year in America. ${ }^{7}$ The traditional method of detecting gallbladder disease had been cholecystography, which has since been replaced by gallbladder sonography. ${ }^{7-9}$ The prevalence of gall bladder disease in sickle cell disease has been stated to be between 4-29\%, in studies carried out independently in Nigeria. Gallstones is also a disorder very common in the female gender. ${ }^{10-12}$ Gallstones are conveniently classified into cholesterol or pigment stones. Cholesterol stones are the commonest type and encountered in industrialized countries, whereas pigment stones are found more frequently in developing countries. $^{3}$
Gallbladder sonography has become the dorminant method of examining the gallbladder. ${ }^{7-9}$ This is so because sonography is a convenient and safe examination as it does not use ionizing radiation, patient preparation or administration of drugs. More importantly, sonographic examination can be easily extended to include the biliary ducts and adjacent organs of the upper abdomen as done in this study. ${ }^{7-10}$ The sensitivity for detecting echogenic bile was about $65.7 \%$ with a specificity of about $96 \% .^{7-9}$

Although the diagnosis of an acute or chronic cholecystitis and gallstones can easily be made clinically, radiological demonstration is required to adequately classify them. Gall bladder sludge occurs often in patients with prolonged fasting, longstanding extra-hepatic cholestasis, various intrinsic disorders of the gall

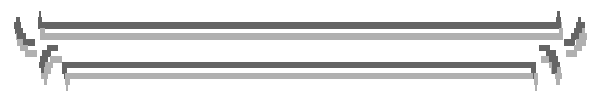


bladder, sickle-cell disease and other causes of haemolysis. Ultrasonographically, the term biliary sludge describes a collection of fine echoes of a lower intensity than those produced by a gallstone. These echoes do not cast an acoustic shadow as seen in this patient and they lie in the most dependent part of the gall bladder. The possibility of artefacts in particular those due to reverberations have to be carefully excluded. $^{2}$

Biliary sludge may become very thick and simulate a gall bladder tumor, termed "tumefactive biliary sludge", which could mimic a gall bladder neoplasm, ${ }^{13-16}$ confusing the inexperienced sonographer as seen in this case. $^{10}$ Biliary sludge moves slowly when the patient changes position and may show evidence of fluid-fluid levels especially in the dependent position. This was observed in this patient. This distinguishes it from small stones and pus, although this sign is not completely reliable. ${ }^{4}$ Other causes of shadowing in the gall bladder on ultrasonographically include pus ${ }^{4}$, the secretion of abnormal mucus ${ }^{4}$, haematobilia ${ }^{5}$, parasites such as ascariasis and distomiasis. ${ }^{6}$

The clinical course of biliary sludge varies. ${ }^{17}$ It often disappears particularly if the causative event is treated. Other cases wax and wane, and some may go on to developing gall stones. Complications of biliary sludge include biliary colic, acute cholangitis, and acute pancreatitis. Asymptomatic patients with biliary sludge require no therapy. When patients are symptomatic as seen in this case report, cholecystectomy is indicated. In the elderly or those at risk from surgery, endoscopic sphincterotomy can prevent recurrent episodes of pancreatitis.

\section{CONCLUSION}

A 24 year old male who developed obstructive jaundice secondary to biliary sludge earlier mis-diagnosed as carcinoma is presented. The need for proper training in ultrasonography to minimize such errors recurring is highlighted.

\section{REFERENCES}

1. Filly RA, Allen $B$, Minton $M J$, Bernohoft R, Way LW.: In-vitro investigation of the origin of echoes within biliary sludge. J Clin Ultrasound 1980: 8:193.

2. Calancy JT, Goddard J, Pearson DC: In-vitro demonstration of cholesterol crystals high echogenicity relative to protein particles. J Clin Ultrasound 1980; 8:27.

3. Moreaux J, Roux JM. Limy bile. A surgical experience in 16 patients. Gastrenterol Clin Biol. 1994; 18: 550-555.

4. Conrad MR, James JO, Dietahy J. Significance of low-level echoes within the gall bladder. Am J Roentgen 1979; 132: 967.

5. Baschi AJ, Norma $A$, Brenbridge AG, Cochrane JA: A further observation on gall bladder debris. J Clin ultrasound 1979: 7; 152.

6. Eisencher A, Sauget Y. Aspect ultrasonores des ascaridioses et distomatoses des voices biliares. Am J Rad. 1980: 161: 319.

7. Wickbom IG, Rentzhog U. The reliability of cholecystography. Acta Radiol Diagn Stockh. 1955; 44: 185-200. 
8. Krook PM, Allen FH, Bush WH, Maimer G, McLean MD. Comparison of real time cholecystosonography and oral cholecystography. Arch Surg 1980; 115: 1096-1098.

9. Lau SWL. Diagnosis of cholelithiasis: Comparison between Oral Cholecystography and Ultrasonography. Radiology 1980: 135; 145-148.

10. Weeks LE, Melune BR, Martin JF: Unusual echographic appearance of a courvoisier gall bladder. J Clin Ultrasound 1977; $5: 341$.

11. Nzeh DA, Adedoyin MA. Sonographic pattern of gallbladder disease in children with sickle cell anaemia. Pediatr Radiol 1989; 19: 290 -292.

12. Durosimi MA, Ogunseinde AO, Olatunji PO, Esan GJF. Prevalence of Cholelithiasis in Nigerians with sickle cell disease. Afr J Med Sci. 1989; $18 ; 223-227$.
13. Fakhry J. Sonography of tumefactive biliary sludge. AJR 1882; 139: 717-719.

14. Anastasi B, Sutherland GR. Biliary sludge- Ultrasonic appearance simulating neoplasm. Br J Radiol 1981; 54: 679-681

15. Braun M, Chaulieu C, Regent D, Claudon M, Bernard C, Treheux A. Tumefactive biliary sludge. Ultrasonic aspects. J Radiol 1986; 67: 341-344

16. Kelly IM, Lees WR, Russell RC. Tumefactive biliary sludge: a sonographic pseudotumour appearance in the common bile duct. Clinic Radiol 1993; 47: 251-224

17. Shaffer EA. Gall bladder sludge: What is its clinical significance? Curr Gastroenterol Rep Apr 2001: 3; 166-73

18. Coakley FV. Magnetic Resonance Cholangiopancreatography. Gastrointestinal 2002; 55: 2-12 